\title{
Enhanced Bean Optimization Algorithm for Solving Reactive Power Problem
}

\author{
Kanagasabai Lenin ${ }^{1}$, Bhumanapally Ravindhranath Reddy ${ }^{1}$, Munagala Suryakalavathi ${ }^{2}$ \\ ${ }^{1}$ Jawaharlal Nehru Technological University (JNTU), Hyderabad, India \\ ${ }^{2}$ Department of Electrical and Electronics Engineering, JNTU, Hyderabad, India \\ Email: "gklenin@gmail.com
}

Received 14 February 2016; accepted 28 February 2016; published 4 March 2016

Copyright (C) 2016 by authors and OALib.

This work is licensed under the Creative Commons Attribution International License (CC BY). http://creativecommons.org/licenses/by/4.0/

CC) (i) Open Access

\begin{abstract}
In this paper an Enhanced Bean Optimization Algorithm (EBA) is used to solve optimal reactive power problem. Stimulated by the diffusion of beans in nature, a novel swarm intelligence algorithm-Bean Optimization Algorithm (BOA) has been projected previously. In the domain of incessant optimization problems solving, Bean Optimization Algorithm has exposed a first-class performance. In this paper, an Enhanced Bean Optimization Algorithm is presented for solving optimal reactive power problem. In this algorithm two novel evolution methodologies named population migration and deductive information cross-sharing are proposed to perk up the performance of Bean Optimization Algorithm. The projected Enhanced Bean optimization algorithm (EBA) has been tested in standard IEEE 30 bus test system and simulation results show clearly the enhanced performance of the projected algorithm in tumbling the real power loss.
\end{abstract}

\section{Keywords}

Bean Optimization Algorithm, Optimization, Optimal Reactive Power, Transmission Loss

Subject Areas: Electric Engineering

\section{Introduction}

Different algorithms are utilized to solve the Reactive Power Dispatch problem. Different types of numerical techniques like the gradient method [1] [2], Newton method [3] and linear programming [4]-[7] have been already used to solve the optimal reactive power dispatch problem. The voltage stability problem plays an important role in power system planning and operation [8]. Evolutionary algorithms such as genetic algorithm, Hybrid differential evolution algorithm, Biogeography Based algorithm, a fuzzy based approach, an improved evolutionary

${ }^{*}$ Corresponding author.

How to cite this paper: Lenin, K., Reddy, B.R. and Suryakalavathi, M. (2016) Enhanced Bean Optimization Algorithm for Solving Reactive Power Problem. Open Access Library Journal, 3: e2464. http://dx.doi.org/10.4236/oalib.1102464 
programming [9]-[15] have been already utilized to solve the reactive power flow problem. In [16]-[18] different methodologies like interior point, upgraded approach are successfully handled the optimal power problem. In [19] [20], a programming based approach and probabilistic algorithm is used to solve the optimal reactive power dispatch problem. This paper proposes an Enhanced bean optimization algorithm (EBA) to solve reactive power dispatch problem. Inspired by the diffusion mode of seeds, a novel swarm intelligence optimization algorithm named Bean Optimization Algorithm (BOA) has been projected already to solve various problems. Bean Optimization Algorithm is mixture of nature evolutionary approach and narrow arbitrary search. Bean Optimization Algorithm has steady robust behavior on explored tests and stands out as a promising alternative to existing optimization methods for engineering applications [21]-[24]. In this paper, an Enhanced Bean Optimization Algorithm (EBA) is presented for solving optimal reactive power problem. Two novel evolution mechanisms named population migration and deductive information cross-sharing are proposed to perk up the performance of Bean Optimization Algorithm. The proposed EBA has been evaluated in standard IEEE 30 bus test system. The simulation results show that the projected approach outperforms all the entitled reported algorithms in minimization of real power loss.

\section{Objective Function}

\subsection{Active Power Loss}

Main aim of the reactive power dispatch problem is to reduce the active power loss in the transmission network, which can be described as:

$$
F=P L=\sum_{k \in N b r} g_{k}\left(V_{i}^{2}+V_{j}^{2}-2 V_{i} V_{j} \cos \theta_{i j}\right)
$$

where $g_{k}$ : is the conductance of branch between nodes $i$ and $j, N b r$ : is the total number of transmission lines in power systems.

\subsection{Voltage Profile Improvement}

For minimization of the voltage deviation in $P Q$ buses, the objective function turns into:

$$
F=P L+\omega_{v} \times V D
$$

where $\omega_{v}$ : is a weighting factor of voltage deviation.

$V D$ is the voltage deviation given by:

$$
V D=\sum_{i=1}^{N p q}\left|V_{i}-1\right|
$$

\subsection{Equality Constraint}

The equality constraint of the Reactive power problem is represented by the power balance equation, and can be written as, where the total power generation must cover the total power demand and total power loss:

$$
P_{G}=P_{D}+P_{L}
$$

where, $P_{G}$-Total Power Generation, $P_{D}$ - Total Power Demand, $P_{L}$-Total Power Loss.

\subsection{Inequality Constraints}

Inequality constraints define the limitations in power system components and power system security. Upper and lower bounds on the active power of slack bus, and reactive power of generators are written as follows:

$$
\begin{gathered}
P_{g s l a c k}^{\min } \leq P_{g s l a c k} \leq P_{g s l a c k}^{\max } \\
Q_{g i}^{\min } \leq Q_{g i} \leq Q_{g i}^{\max }, i \in N_{g}
\end{gathered}
$$

Upper and lower bounds on the bus voltage magnitudes are described as follows:

$$
V_{i}^{\min } \leq V_{i} \leq V_{i}^{\max }, i \in N
$$


Upper and lower bounds on the transformers tap ratios are given as follows:

$$
T_{i}^{\min } \leq T_{i} \leq T_{i}^{\max }, i \in N_{T}
$$

Upper and lower bounds on the compensators reactive powers are written as follows:

$$
Q_{c}^{\min } \leq Q_{c} \leq Q_{C}^{\max }, i \in N_{C}
$$

where $N$ is the total number of buses, $N_{T}$ is the total number of Transformers; $N_{c}$ is the total number of shunt reactive compensators.

\section{Bean Optimization Algorithm}

Stimulated by the diffusion mode of beans, Bean Optimization Algorithm (BOA) has been proposed previously to solve the various problems. In BOA, the position of an individual bean is articulated with real number vector and written as

$$
Y=\left\{y_{1}, y_{2}, y_{3}, \cdots, y_{n}\right\}
$$

where $n$ is determined by the scale of problem .Bean group is comprises of large number of beans. The size of the bean group can be attuned depending upon realistic problems. In adding to the above, beans are propagated to the region and the area is defined by the type of problem. Father beans are those beans whose fitness value is greater than others. In BOA, the number and distribution of offspring beans will be placed according to their father bean's fitness value. The fundamental equation of BOA is written as follows,

$$
Y[i]=\left\{\begin{array}{l}
Y[i], \text { if } Y[i] \text { is father Bean } \\
Y_{n b}+\operatorname{Distribution}\left(Y_{n b}\right) \times D, \\
\text { if } Y[i] \text { is not father Bean }
\end{array}\right.
$$

In the above equation, $Y[i]$ is the position of bean $i . Y_{n b}$ is the position of the father bean. Distribution $(Y)$ is an arbitrary variable with a definite distribution of father bean in order to get the positions of its offspring's. Parameter $D$ can be set according to the range of the problem to be resolved. In adding to that, the allocation of some beans does not follow the equation Reported above. They select arbitrary positions in order to emphasize the global optimization performance. When the offspring beans finished positioning, their fitness value has to be calculated. The beans with most optimal fitness value will be chosen as the candidates of father beans in the subsequent generation. The candidates of father beans should also gratify the condition that the distance between every two father beans should be greater than the distance threshold. This condition assures that the father beans can have a superior distribution to keep away from early convergence and augment the performance of the BOA. If all the conditions are satisfied, then the candidate can be set as the father bean for subsequent generation.

\section{Enhanced Bean Optimization Algorithm}

Bean Optimization Algorithm (BOA) utilizes population evolution mechanism for solving optimization problems. Since most of the population evolution methods are continuous, they are complicated to solve discrete optimization problems. In this paper an Enhanced Bean Optimization Algorithm (EBA) is utilized for solving Reactive Power Problem.

The algorithm model can be described as follows,

1) Individual beans

The position vector of an individual bean is located as

$$
Y=\left\{y_{1}, y_{2}, y_{3}, \cdots, y_{n}\right\} .
$$

The above indicates that there is a route as

$$
y_{1} \rightarrow y_{2} \rightarrow \cdots y_{n} \text { and } y_{i} \neq y_{j}(i \neq j) .
$$


2) Population progress

In the procedure of population migration, minimum two populations should be initialized. The father bean in each population will be mixed up in cross-species process through the interaction between populations in order to endorse the affluence of populations.

3) Cross-sharing of deductive information

In order to keep the deductive information of the father beans, there are cross operations between the father beans and the individual beans to create new offspring's.

The explicit operation is shown as follows.

1) Pick an arbitrary position in the vectors of a father bean $f$ and an individual bean $s$ separately as a cross-region.

2) Swap cross-region between $f$ and $s$. Then remove the duplicate elements in $f$ and $s$ separately. Two new offspring individuals' $g$ and $h$ will be produced.

In EBA, the first step is population has to be initiated (let the size of population be $n$ ). According to the fitness values of individual beans, choose the father beans (let the number of father beans be three): $R_{1}, R_{2}, R_{3}$. $(n-3) / 3$ individuals will be displayed as sub-populations " 1 " according to the Euclidean distance between individual beans and $R_{1}$. By using same method, sub-populations 2 and sub-population 3 will be produced. Then let $R_{2}$ be the cross father bean of sub-population 3 and cross operations will be carried out between $R_{2}$ and individual beans in sub-population 3. Choose the offspring with the most excellent fitness value to shift the previous individual bean in sub-population 3. Let $R_{3}$ be the cross father bean of sub-population 1 and cross operations will be carried out between $R_{3}$ and individual beans in sub-population 1. Pick the offspring with the most excellent fitness value to shift the former individual bean in sub-population 1 . Let $R_{1}$ be the cross father bean of sub-population 2 and cross operations will be carried out between $R_{1}$ and individual beans in sub-population 2. Choose the offspring with the most excellent fitness value to relocate the previous individual bean in sub-population 2 .

Reiterate the above procedure until the termination condition is met.

\section{EBA for solving Optimal Reactive Power problem}

Set the number of iterations be $S$.

Arbitrarily produce $\mathrm{n}$ initial beans.

Compute the fitness value of the preliminary beans and Select $S$ father beans.

Create $z$ sub-populations by using clustering algorithm.

While (the number of iterations $<S$ )

For $i=1: S$

For $j=1: n$

Cross operations are carried out between $Y_{j}$ and $R_{(i+1)}$;

The bean with the best fitness value is recorded as $Y_{j 1}$;

$Y_{i}=Y_{j 1}$;

End

Modernize the Father beans;

End

End

Output the finest solution.

\section{Simulation Results}

Enhanced Bean Algorithm has been tested in IEEE 30-bus, 41 branch system. The system has 6 generator-bus voltage magnitudes, 4 transformer-tap settings, and 2 bus shunt reactive compensators. Bus 1 is considered as slack bus and 2, 5, 8, 11 and 13 are considered as PV generator buses and the other buses are taken as PQ load buses. Generators buses (PV) are 2, 5, 8, 11, 13 and slack bus is 1. Control variables limits are listed in Table 1. The power limits generators buses are displayed in Table 2. Table 3 shows the projected approach succeeded in keeping the control variables within limits.

Table 4 narrates about the performance of the proposed EBA algorithm. Figure 1 explains about the convergence characteristics of the proposed EBA where it took 25 iterations to converge. Figure 2 shows about the voltage deviations during the iterations in the low, medium and high level through EBA method. Table 5 summarizes the results of the optimal solution obtained by various standard methods. 
Table 1. BASIC variable limits (PU).

\begin{tabular}{cccc}
\hline List of Variables & Min. Value & Max. Value & Category \\
\hline Generator Bus & 0.90 & 1.08 & Continuous \\
Load Bus & 0.90 & 1.01 & Continuous \\
Transformer-Tap & 0.91 & 1.00 & Discrete \\
Shunt Reactive Compensator & -0.10 & 0.30 & Discrete \\
\hline
\end{tabular}

Table 2. List of generators power limits.

\begin{tabular}{ccccc}
\hline Bus & Pg. & Pgmin & Pgmax & Qgmin \\
\hline 1 & 90.00 & 47 & 121 & -20 \\
2 & 82.00 & 18 & 75 & -20 \\
5 & 50.00 & 10 & 41 & -11 \\
8 & 20.00 & 10 & 32 & -13 \\
11 & 20.00 & 10 & 19 & -10 \\
13 & 20.00 & 11 & 35 & -13 \\
\hline
\end{tabular}

Table 3. Control variables values after optimization.

\begin{tabular}{ccc}
\hline Control Variables & EBA \\
\hline V1 & 1.0612 \\
V2 & 1.0503 \\
V5 & 1.0312 \\
V8 & 1.0417 \\
V11 & 1.0814 \\
V13 & 1.0601 \\
T4, 12 & 0.00 \\
T6, 9 & 0.01 \\
T6, 10 & 0.90 \\
T28, 27 & 0.90 \\
Q10 & 0.11 \\
Q24 & 0.11 \\
Real power loss & 4.2781 \\
Voltage deviation & 0.9057 \\
\hline
\end{tabular}

Table 4. Performance of EBA algorithm.

\begin{tabular}{cr}
\hline Iterations & 25 \\
Time taken (secs) & 4.32 \\
Real power loss & 4.2781 \\
\hline
\end{tabular}




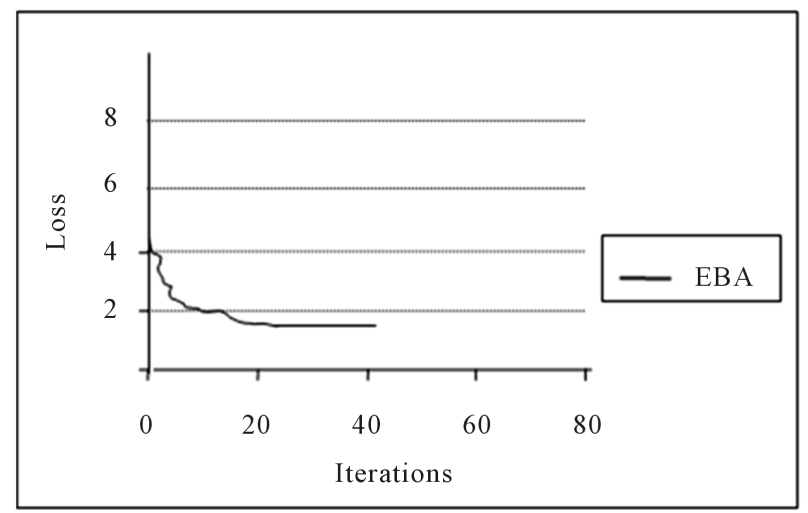

Figure 1. Convergence characteristics.

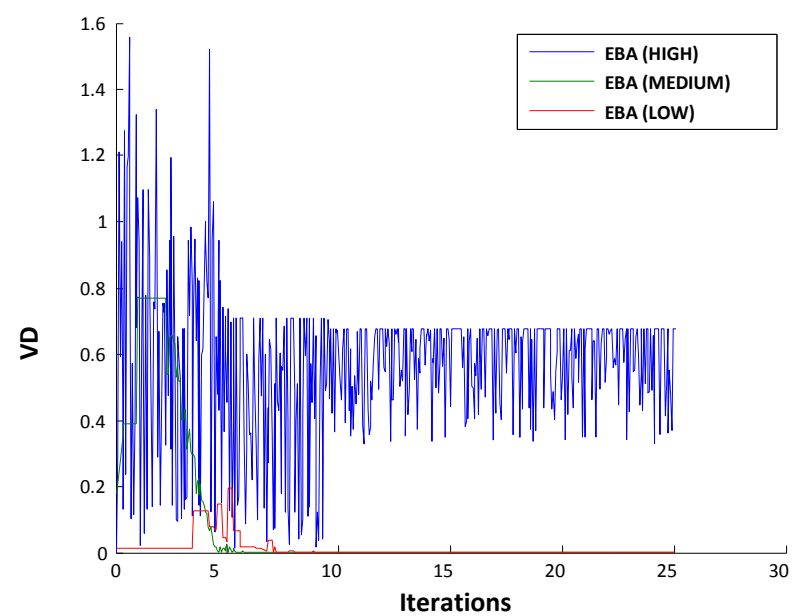

Figure 2. Voltage deviation (VD) characteristics.

Table 5. Comparison of real power loss.

\begin{tabular}{cc}
\hline Methods & Real power loss (MW) \\
SGA [25] & 4.98 \\
PSO [26] & 4.9262 \\
LP [27] & 5.988 \\
EP [27] & 4.963 \\
CGA [27] & 4.980 \\
AGA [27] & 4.926 \\
CLPSO [27] & 4.7208 \\
HSA [28] & 4.7624 \\
BB-BC [29] & 4.690 \\
EBA & 4.2781 \\
\hline
\end{tabular}

\section{Conclusion}

In this paper, Enhanced Bean Optimization Algorithm (EBA) has been efficiently solved the Optimal Reactive Power Dispatch problem. The projected algorithm has been tested in standard IEEE 30 bus system. Simulation 
study shows the robustness of projected Enhanced Bean Optimization Algorithm (EBA) method in providing improved optimal solution by decreasing the real power loss. The control variables values obtained after the optimization by Enhanced Bean Optimization Algorithm (EBA) are well within the limits.

\section{References}

[1] Alsac, O. and Scott, B. (1974) Optimal Load Flow with Steady State Security. IEEE Transactions on Power Apparatus and Systems, PAS-93, 745-751.

[2] Lee, K.Y., Paru, Y.M. and Oritz, J.L. (1985) A United Approach to Optimal Real and Reactive Power Dispatch. IEEE Transactions on Power Apparatus and Systems, PAS-104, 1147-1153. http://dx.doi.org/10.1109/TPAS.1985.323466

[3] Monticelli, A., Pereira, M.V.F. and Granville, S. (1987) Security Constrained Optimal Power Flow with Post Contingency Corrective Rescheduling. IEEE Transactions on Power Systems, 2, 175-182. http://dx.doi.org/10.1109/TPWRS.1987.4335095

[4] Deeb, N. and Shahidehpur, S.M. (1990) Linear Reactive Power Optimization in a Large Power Network Using the Decomposition Approach. IEEE Transactions on Power System, 5, 428-438. http://dx.doi.org/10.1109/59.54549

[5] Hobson, E. (1980) Network Constrained Reactive Power Control Using Linear Programming. IEEE Transactions on Power Systems, PAS-99, 868-877.

[6] Lee, K.Y., Park, Y.M. and Oritz, J.L. (1984) Fuel-Cost Minimisation for Both Real and Reactive Power Dispatches. IEE Proceedings C-Generation, Transmission and Distribution, 131, 85-93.

[7] Mangoli, M.K. and Lee, K.Y. (1993) Optimal Real and Reactive Power Control Using Linear Programming. Electric Power Systems Research, 26, 1-10. http://dx.doi.org/10.1016/0378-7796(93)90063-K

[8] Canizares, C.A., de Souza, A.C.Z. and Quintana, V.H. (1996) Comparison of Performance Indices for Detection of Proximity to Voltage Collapse. IEEE Transactions on Power Systems, 11, 1441-1450.

[9] Paranjothi. S.R. and Anburaja, K. (2002) Optimal Power Flow Using Refined Genetic Algorithm. Electric Power Components and Systems, 30, 1055-1063. http://dx.doi.org/10.1080/15325000290085343

[10] Devaraj, D. and Yeganarayana, B. (2005) Genetic Algorithm Based Optimal Power Flow for Security Enhancement. IEE Proceedings_Generation, Transmission and Distribution, 152, 899. http://dx.doi.org/10.1049/ip-gtd:20045234

[11] Berizzi, A., Bovo, C., Merlo, M. and Delfanti, M. (2012) A GA Approach to Compare ORPF Objective Functions Including Secondary Voltage Regulation. Electric Power Systems Research, 84, 187-194. http://dx.doi.org/10.1016/j.epsr.2011.11.014

[12] Yang, C.-F., Lai, G.G., Lee, C.-H., Su, C.-T. and Chang, G.W. (2012) Optimal Setting of Reactive Compensation Devices with an Improved Voltage Stability Index for Voltage Stability Enhancement. International Journal of Electrical Power and Energy Systems, 37, 50-57. http://dx.doi.org/10.1016/j.ijepes.2011.12.003

[13] Roy, P., Ghoshal, S. and Thakur, S. (2012) Optimal VAR Control for Improvements in Voltage Profiles and for Real Power Loss Minimization Using Biogeography Based Optimization. International Journal of Electrical Power and Energy Systems, 43, 830-838. http://dx.doi.org/10.1016/j.ijepes.2012.05.032

[14] Venkatesh, B., Sadasivam, G. and Khan, M. (2000) A New Optimal Reactive Power Scheduling Method for Loss Minimization and Voltage Stability Margin Maximization Using Successive Multi-Objective Fuzzy LP Technique. IEEE Transactions on Power Systems, 15, 844-851. http://dx.doi.org/10.1109/59.867183

[15] Yan, W., Lu, S. and Yu, D. (2004) A Novel Optimal Reactive Power Dispatch Method Based on an Improved Hybrid Evolutionary Programming Technique. IEEE Transactions on Power Systems, 19, 913-918. http://dx.doi.org/10.1109/TPWRS.2004.826716

[16] Yan, W., Liu, F., Chung, C. and Wong, K. (2006) A Hybrid Genetic Algorithm Interior Point Method for Optimal Reactive Power Flow. IEEE Transactions on Power Systems, 21, 1163-1169. http://dx.doi.org/10.1109/TPWRS.2006.879262

[17] Yu, J., Yan, W., Li, W., Chung, C. and Wong, K. (2008) An Unfixed Piecewise-Optimal Reactive Power-Flow Model and Its Algorithm for Ac-Dc Systems. IEEE Transactions on Power Systems, 23, 170-176. http://dx.doi.org/10.1109/TPWRS.2007.907387

[18] Capitanescu, F. (2011) Assessing Reactive Power Reserves with Respect to Operating Constraints and Voltage Stability. IEEE Transactions on Power Systems, 26, 2224-2234. http://dx.doi.org/10.1109/TPWRS.2011.2109741

[19] Hu, Z., Wang, X. and Taylor, G. (2010) Stochastic Optimal Reactive Power Dispatch: Formulation and Solution Method. International Journal of Electrical Power and Energy Systems, 32, 615-621.

[20] Kargarian, A., Raoofat, M. and Mohammadi, M. (2012) Probabilistic Reactive Power Procurement in Hybrid Electricity Markets with Uncertain Loads. Electric Power Systems Research, 82, 68-80. http://dx.doi.org/10.1016/j.epsr.2011.08.019 
[21] Zhang, X., Wang, R. and Song, L. (2008) A Novel Evolutionary Algorithm—Seed Optimization Algorithm. Pattern Recognition and Artificial Intelligence, 21, 677-681.

[22] Wang, P. and Cheng, Y. (2010) Relief Supplies Scheduling Based on Bean Optimization Algorithm. Economic Research Guide, No. 8, 252-253.

[23] Zhang, X., Sun, B., Mei, T. and Wang, R. (2010) Post-Disaster Restoration Based on Fuzzy Preference Relation and Bean Optimization Algorithm. In: Proceedings of the 2010 IEEE Youth Conference on Information, Computing and Telecommunications, IEEE Press, New York, 253-256.

[24] Li, Y. (2010) Solving TSP by an ACO-and-BOA-Based Hybrid Algorithm. In: Proceedings of the 2010 International Conference on Computer Application and System Modeling, IEEE Press, New York, 189-192.

[25] Wu, Q.H., Cao, Y.J. and Wen, J.Y. (1998) Optimal Reactive Power Dispatch Using an Adaptive Genetic Algorithm. International Journal of Electrical Power \& Energy Systems, 20, 563-569. http://dx.doi.org/10.1016/S0142-0615(98)00016-7

[26] Zhao, B., Guo, C.X. and Cao, Y.J. (2005) Multiagent-Based Particle Swarm Optimization Approach for Optimal Reactive Power Dispatch. IEEE Transactions on Power Systems, 20, 1070-1078. http://dx.doi.org/10.1109/TPWRS.2005.846064

[27] Mahadevan, K. and Kannan, P.S. (2010) Comprehensive Learning Particle Swarm Optimization for Reactive Power Dispatch. Applied Soft Computing, 10, 641-652. http://dx.doi.org/10.1016/j.asoc.2009.08.038

[28] Khazali, A.H. and Kalantar, M. (2011) Optimal Reactive Power Dispatch Based on Harmony Search Algorithm. Electrical Power and Energy Systems, 33, 684-692. http://dx.doi.org/10.1016/j.ijepes.2010.11.018

[29] Sakthivel, S., Gayathri, M. and Manimozhi, V. (2013) A Nature Inspired Optimization Algorithm for Reactive Power Control in a Power System. International Journal of Recent Technology and Engineering (IJRTE), 2, 29-33. 